\title{
Relação entre Consciência Morfológica e Leitura Contextual Medida pelo Teste de Cloze
}

\author{
The Relationship between Morphological Awareness and Contextual \\ Reading Measured by the Cloze Test
}

\author{
Márcia Maria Peruzzi Elia da Mota*, ${ }^{*}$, Rafaela Lisboa ${ }^{a}$, Jaqueline Dias $^{a}$, Rhaisa Gontijo ${ }^{a}$, Nádia \\ Paiva $^{a}$, Stella Mansur-Lisboa ${ }^{a}$, Danielle Andrade Silva ${ }^{a} \&$ Acácia Aparecida Angeli dos Santos ${ }^{b}$ \\ ${ }^{a}$ Universidade Federal de Juiz de Fora \\ ${ }^{b}$ Universidade São Francisco
}

\begin{abstract}
Resumo
Consciência morfológica é a habilidade de refletir sobre os morfemas que compõem as palavras. Esta habilidade está associada à leitura e escrita e parece ser particularmente importante para compreensão de texto e leitura contextual, visto que além das informações fonológicas, informações sintático-semânticas devem ser utilizadas. Este estudo se propôs a investigar a relação entre a consciência morfológica e a compreensão de texto medida pelo Cloze. Na primeira parte foi explorada a relação entre as tarefas de consciência morfológica e os escores no Cloze através de correlações simples e, na segunda parte, averiguou-se a especificidade desta relação. Os resultados mostram que a consciência morfológica está associada à leitura contextual no português e que, até certo ponto, essa contribuição é independente do processamento fonológico.

Palavras-chave: Consciência metalingüística; avaliação; teste de Cloze; leitura.

Abstract

Morphological awareness is the awareness of the morphemes of the words. This ability is related to spelling, reading and it seems to be particularly important for reading comprehension and contextual reading. In this kind of reading besides phonological information, syntactic-semantic information is required as well. This study intends to investigate the relationship between morphological awareness and reading comprehension measured by the Cloze Test. In the first part of the study the relationship between the Cloze test scores and morphological awareness are explored by simple correlations. In the second part, the specificity of this relationship is further explored. The results showed that to some extent this relationship is independent of phonological awareness.

Keywords: Metalinguistic awareness; assessment; Cloze test; reading.
\end{abstract}

A revisão de literatura sobre a temática permite constatar que nos últimos 30 anos houve um aumento expressivo do número de estudos que investigaram a relação entre a consciência metalingüística e a alfabetização (Bowey, 2005; Bradley \& Bryant, 1983; Gombert, 1992; Plaza \& Cohen, 2003, 2004). Dentre as habilidades metalingüísticas, três se destacam por contribuírem de forma causal para o sucesso na alfabetização, quais sejam, a consciência fonológica, a consciência sintática e a consciência morfológica.

Dentre elas, a mais estudada é a consciência fonológica, que pode ser definida como a habilidade de refletir sobre

*Endereço para correspondência: Universidade Federal de Juiz de Fora, Instituto de Ciências Humanas, Campus Universitário Martelos, Juiz de Fora, MG, Brasil, CEP 36036330.E-mail:mmotapsi@pesquisador.cnpq.br Agradecimentos ao financiamento do Conselho Nacional de Desenvolvimento Científico e Tecnológico (CNPq), Edital Ministério da Ciência e Tecnologia (MCT)/CNPq 50/2006 Ciências Humanas, Sociais e Sociais Aplicadas.

Bolsista de Iniciação Científica do CNPq Stella Mansur-Lisboa. Comitê de ética: (protocolo Comitê de Ética em Pesquisa (CEP)/ Universidade Federal de Juiz de Fora (UFJF) 956002 2007). os sons que compõem a fala (Cardoso-Martins, 1995). Estudos demonstram que a consciência fonológica ajuda na alfabetização, e que o treinamento dessa habilidade freqüentemente tem sido utilizado visando a remediação dos problemas de leitura (Bradley \& Bryant, 1985; Cunningham, 1990; Goswami \& Bryant, 1990). No Brasil os trabalhos de Capovilla e Capovilla (2000), CardosoMartins (1995), Guimarães (2003), Maluf e Barrera (1997), e Santos (1996), só para citar alguns, confirmam a importância do tema para a aquisição da língua escrita no português brasileiro.

Embora a consciência fonológica geralmente esteja associada à decodificação de palavras, diversos estudos têm demonstrado que essa habilidade contribui para a compreensão de leitura, à medida que favorece a leitura contextual (Rego, 1995; Rego \& Bryant, 1993; Tunmer, 1990). Isso ocorre provavelmente porque a automatização da decodificação acelera o processo de reconhecimento das palavras no texto o que, por sua vez, libera espaço da memória para armazenamento do texto, facilitando o processo de compreensão (Stanovich, 1980). 
A consciência fonológica não é a única habilidade a facilitar o processo de alfabetização. Um novo corpo de evidências vem se formando, apontando para o papel facilitador da consciência morfológica na aquisição da leitura e escrita (Carlisle, 1995; Deacon \& Kirby, 2004; Nagy, Berninger, \& Abbot, 2006). Sob essa perspectiva, a habilidade de refletir sobre os morfemas, menores unidades linguiísticas que têm significado próprio, é chamada consciência morfológica (Carlisle, 1995). Vale acrescentar que essa habilidade pode ajudar na alfabetização porque a ortografia de muitas palavras depende da morfologia. Palavras como "laranjeira", que têm ortografia ambígua, podem ser escritas de forma correta se soubermos sua origem: "laranja". Os significados delas podem ser igualmente inferidos na leitura, se o leitor souber o significado da palavra que as originou.

A explicação da importância do processamento morfológico para leitura é apresentada por Mann (2000), que aponta duas razões para tanto. A primeira diz respeito à argumentação de que a escrita pode ser analisada em vários níveis, que não só o fonológico. Um deles é o nível semiográfico, que implica estabelecer como os grafemas representam os significados das palavras (Marec-Breton \& Gombert, 2004). Considerando que os morfemas são unidades de significado, pode-se hipotetizar que a consciência morfológica pode facilitar a aquisição do princípio semiográfico. A segunda razão refere-se mais especificamente à natureza da ortografia focalizada. Aqui é importante ressaltar que a argumentação principal para a relação encontrada entre o processamento morfológico e a alfabetização vem de pesquisas realizadas em falantes do inglês, língua nativa de Mann (2000) e dos sujeitos por ela estudados.

Nesse sentido, vale ainda lembrar que o princípio alfabético é o de que letras devem corresponder perfeitamente aos sons das palavras, mas que as línguas alfabéticas variam quando ao grau de correspondência entre as letras e os sons da fala. No inglês essas relações são mais opacas do que em ortografias como o finlandês, o português ou o espanhol. Muitas das irregularidades encontradas no inglês podem ser explicadas pela estrutura morfológica das palavras (Chomsky \& Halle, 1968; Sterling, 1992). Por exemplo, no inglês a palavra 'heal' que rima com ' $i l$ ' e a palavra 'health' que rima com 'elf' têm a mesma origem semântica; por isso são escritas da mesma forma, embora sejam pronunciadas de forma diferente.

Nas línguas com ortografias mais regulares o processamento morfológico pode não contribuir de forma significativa para aquisição e processamento da língua escrita, porque a maioria das palavras pode ser escrita aplicando-se o princípio alfabético. Mann (2000) supõe que as línguas alfabéticas mais regulares podem ser mais dependentes da estrutura fonológica das palavras do que da estrutura morfológica.

Lehtonen e Bryant (2005) ressaltam que embora este seja um argumento válido, a hipótese de que a consciência morfológica contribui para alfabetização, também nas ortografias regulares é pertinente, argumentando que essa é uma questão teórica que precisa ser mais bem investigada. De fato, no inglês, em uma série de estudos que exploraram a relação entre a consciência morfológica e a alfabetização, Joanne Carlisle mostrou que a habilidade de refletir sobre os morfemas das palavras estava associada ao desempenho na leitura de palavras isoladas e, à compreensão de leitura (Carlisle, 1995, 2000; Carlisle \& Fleming, 2003), e também ao desempenho da escrita (Carlisle, 1988, 1996).

Em acréscimo, é relevante ponderar que não é apenas em línguas com estrutura fonológica opaca que a consciência morfológica contribui para a aquisição da língua escrita. No francês, Colé, Marec-Breton, Royer e Gombert (2003) evidenciaram um fator facilitador da consciência morfológica na leitura de palavras isoladas em crianças de primeira série. Mesmo para a língua portuguesa já há alguns estudos que têm mostrado a relação entre a consciência morfossintática e a escrita (Queiroga, Lins, \& Pereira, 2006; Rego, 1995).

Essa visão também é corroborada por Rego e Bryant (1993) quando argumentam que diferentes aspectos da consciência metalingüística podem contribuir de maneira diversa para a leitura e escrita. Na leitura, além de processadas, as pistas grafo-fonêmicas são associadas aos sons das palavras. Neste caso, informações visuais, contextuais e fonológicas já apresentadas no texto ajudam na leitura. A habilidade de refletir sobre a estrutura sintática das sentenças, denominada freqüentemente como consciência sintática, pode ajudar a criança a utilizar pistas contextuais para ler. O uso de informações contextuais na leitura, conhecido como processo top down, torna-se importante para o leitor principiante ou para crianças com dificuldades de leitura que se valem do contexto para auxiliá-las, haja vista a dificuldade que apresentam para a decodificação das palavras (Nicholson, 1993; Stanovich, 1980).

Ainda nessa direção, Rego e Bryant (1993) testaram essa hipótese em crianças inglesas. Verificaram que embora a consciência fonológica e a sintática contribuíssem para uma porção significativa na variância em testes de leitura, no caso da escrita somente a consciência fonológica contribuía de forma estatisticamente significativa.

Posteriormente, Rego (1995) investigou a contribuição da consciência sintática para a leitura de palavras em isolamento e no contexto entre crianças brasileiras. Em um estudo longitudinal com crianças pré-leitoras, Rego mediu a habilidade das crianças corrigirem palavras desordenadas numa frase (tarefa de consciência sintática). Cerca de um ano mais tarde, a autora mediu a habilidade das crianças lerem pseudopalavras, palavras isoladas e palavras inseridas num contexto. Se a consciência sintática contribuísse para a decodificação na leitura, então os escores na tarefa de consciência sintática deveriam predizer os escores na tarefa de leitura de pseudopalavras.

Os resultados das correlações feitas entre as diversas medidas tomadas por Rego (1995) mostraram que a medida de consciência sintática correlacionou-se de forma estatisticamente significativa e positiva com a tarefa de facilitação contextual, mas não com a tarefa de leitura de 
Mota, M. M. P. E., Lisboa, R., Dias, J., Gontijo, R., Paiva, N., Mansur-Lisboa, S., Silva, D. A. \& Santos, A. A. A. (2009). Relação entre Consciência Morfológica e Leitura Contextual Medida pelo Teste de Cloze.

palavras isoladas ou de palavras inventadas. O resultado da regressão múltipla que avaliou a contribuição dos escores na tarefa de consciência sintática para a leitura contextual um ano depois, mostrou um resultado estatisticamente significativo, mesmo depois de serem controladas a idade e os escores na tarefa de memória de trabalho. A autora concluiu que, no caso do português, e provavelmente, de outras ortografias regulares, as pistas sintático-semânticas não ajudam no entendimento das regras de correspondência entre letra e som como foi proposto por Tunmer (1990), mas sim na utilização de pistas contextuais na leitura.

Assim sendo, há uma importante questão conceitual a ser discutida e mais bem investigada. Também é relevante acentuar que até recentemente os termos 'consciência morfológica' e 'consciência sintática' eram usados como sinônimos. Embora o emprego da expressão 'consciência sintática' tenha sido usado para tarefas que envolvem tanto aspectos mais gerais da sintaxe da língua, quanto para tarefas que envolvem aspectos morfológicos, alguns autores já fazem a distinção entre essas habilidades, preferindo a utilização do termo morfossintaxe ou consciência gramatical (Bowey, 2005; Correa, 2005).

Considerando os aspectos assinalados, o presente estudo foi proposto com o intuito de investigar a relação entre a consciência morfológica, em particular a consciência da morfologia derivacional, e a leitura contextual em uma amostra de crianças brasileiras. Julgou-se importante também explorar a especificidade desta relação, visto que há pesquisas que apontam para a existência de correlações positivas e significativas entre a consciência morfológica e a leitura contextual (Nagy et al., 2006). Porém essa relação pode ser mediada pela consciência fonológica (Deacon $\&$ Kirby, 2004). Diferentemente do aqui proposto, tais estudos têm sido realizados com crianças mais velhas.

Por último, importa enfatizar que o presente estudo partiu do pressuposto de que a consciência morfológica faz parte do conjunto de habilidades metalingüísticas relevantes para a alfabetização, pretendendo analisar o quanto da variância do fenômeno seria explicado por ela. Dessa forma optou-se pelo controle da variância atribuída à consciência fonológica e pelo uso do teste de Cloze, visto que sua forma de elaboração permite que se analise o quanto o leitor se apóia nas pistas do contexto e/ou em conhecimentos prévios (Maki, Schields, Wheeler, \& Zacchini, 2005; Santos, 2004; Santos, Primi, Taxa, \& Vendramini, 2002). Em outras palavras, duas questões foram propostas para ser investigadas, a saber, (a) A consciência morfológica está associada à leitura contextual? (b) Essa associação se mantém se a variância devida à consciência fonológica for controlada?

\section{Método}

\section{Participantes}

A amostra do estudo foi constituída por 42 crianças, sendo 19 alunas da $1^{\mathrm{a}}$ série e 23 da $2^{\mathrm{a}}$ série, ambas do ensino fundamental de escolas particulares, situadas no interior de Minas. A média de idade das crianças de $1^{\text {a }}$ série foi de
87,5 meses $(D P=3,93)$ e a da segunda série 98,3 meses $(D P=4,58)$. As crianças foram convidadas a participar através de uma carta convite. A participação no estudo dependeu da autorização do responsável através do Termo de Consentimento Livre e Esclarecido.

\section{Instrumentos}

Tarefas de Consciência Morfológica

Tarefas de Decisão Morfo-Semântica - Raiz (uma variação de Besse, Vidigal de Paula, \& Gombert, comunicação pessoal, setembro de 2005). Inicialmente delineada para crianças mais velhas do que as que participaram deste estudo, o que levou à necessidade de simplificar a tarefa original. Assim, foi criada uma variação da mesma visando investigar o conhecimento da raiz das palavras, visto que a criança tinha que decidir qual palavra era da mesma família que a palavra alvo. Utilizamos o termo variação e não adaptação, pois se tratou de uma modificação da tarefa e não uma adaptação da mesma para o contexto deste estudo.

Os pares de palavra foram escolhidos em razão do número de letras e da freqüência de ocorrência na escrita, todas elas extraídas da tabela para primeira série proposta por Pinheiro (1996). Como não há índices de familiaridade para o português as palavras foram pareadas por frequiência para garantir minimamente um equilíbrio na familiaridade das palavras. A lista de palavras consistia de dez grupos de três palavras envolvendo prefixos (Ex: Tornar - Retorna - Resolve) e dez grupos de palavra envolvendo sufixos (Ex. Pinta - Tambor - Pintor). As crianças poderiam obter um total de 10 pontos nessa análise.

Tarefa de Decisão Morfo-semântica (Besse et al., comunicação pessoal, setembro de 2005). Nesta tarefa a criança tinha que decidir se uma palavra era construída da mesma forma que as outras. A lista de palavras consistia de 12 grupos de três palavras envolvendo prefixos (Ex. Cansar Descanso - Desmaio) e 12 grupos de palavra envolvendo sufixos (Ex. Leite - Ligeira - Leiteira). As crianças poderiam ter um total de 12 pontos nessa tarefa.

Tarefa de Associação Morfo-Semântica (Nagy et al., 2006). Nesta tarefa a criança tinha que decidir se duas palavras eram da mesma família ou de famílias diferentes. Onze pares de palavras foram criados, seis pares pertenciam à mesma família (Ex. banho-banheiro) e cinco eram de famílias diferentes (Ex. chique-chiqueiro). Todas as palavras partilhavam do mesmo som inicial, de maneira que diferenças no desempenho não poderiam ser atribuídas à semelhança fonológica, mas ao conhecimento da relação morfo-semântica das palavras. As crianças podiam ter um total de onze pontos.

Tarefa de Analogia Gramatical (adaptada de Nunes, Bindman, \& Bryant, 1997). A tarefa inicial de Nunes et al. (1997) foi adaptada, considerando a especificidade da morfologia derivacional do português. Sob essa perspectiva, foram criados dez itens, a partir dos quais a criança devia produzir uma palavra morfologicamente complexa a partir de uma palavra alvo, aplicando a mesma relação de derivação de um par previamente dado. O total de pontos possíveis era 10. 
Tarefas de Consciência Fonológica. Foi usada a versão brasileira adaptada por Cardoso Martins (1997) do oddity test de Bradley e Bryant (1983), investigando a categorização de rima e aliteração. Nesta tarefa a criança deve decidir qual palavra não tem o mesmo som que outras em duas listas, sendo a primeira de rima (Ex. 'morcego', 'panela' e 'janela') e a segunda de aliteração (Ex., 'selo', 'casa' e 'sopa'). Nesta tarefa eram 12 pontos possíveis no total.

Cloze: Teste de Compreensão de Leitura. O Cloze, tal como criado por Taylor em 1958 consiste de um texto do qual se suprimem alguns vocábulos, e se pede ao leitor que preencha os espaços com as palavras que melhor completarem o sentido do texto. Para o presente estudo foram escolhidos dois textos, cujas propriedades psicométricas já tinham sido estabelecidas em estudo anterior no Brasil (Santos, 2005). Assim sendo, já havia sido identificado que ambos apresentavam evidências de validade (convergente e de critério) e também índices de consistência interna satisfatórios (á>0,70). O número de acertos possíveis para cada um dos textos é de 15 pontos, perfazendo o total de 30 pontos quando se considera o conjunto das duas histórias.

Desempenho Escolar. Foram utilizados os itens de leitura de palavras isoladas e escrita do Teste de Desempenho Escolar-TDE (Stein, 1994). Por meio deste instrumento, que apresenta propriedades psicométricas satisfatórias, incluindo evidências de validade de critério e bom índice de consistência interna (á>0,70), foi avaliado o desempenho na leitura e escrita das crianças.

Inteligência. Os sub-testes de Vocabulário e Dígitos da Escala de Inteligência Wechsler para crianças-WISC III (Wechsler, 1991) foram utilizados. Os escores ponderados foram selecionados para as análises estatísticas. Os coeficientes de fidedignidade para esses sub-testes foram calculados pelo método de Guttmam e mostram que apresentam bons índices de consistência interna (coeficientes maiores que 0,60$)$.

\section{Procedimento}

As crianças foram avaliadas individualmente em três sessões de 20 a 30 minutos. Na primeira delas foram realizados os testes de consciência morfológica e de consciência fonológica, aplicados tal como descrito a seguir.

Nas Tarefas de Decisão Morfo-semântica - raiz (uma variação de Besse et al., comunicação pessoal, setembro de 2005) era dada a seguinte instrução:

algumas palavrinhas são da mesma família do que outras. Por exemplo, a palavra 'conta' e a palavra 'reconta' são da mesma família. Já a palavra 'bola' e 'rebola' não são da mesma família. Eu vou falar para você uma palavra e depois vou falar mais outras duas e você vai me dizer qual das duas é da mesma família da primeira.

Por fim, realizava-se um exemplo com a criança: “a palavra 'gela' é da mesma família que 'congela' ou 'conversa'?" Caso a criança errasse, explicava-se a forma correta, e se acertasse iniciava-se a tarefa. Depois do exemplo, iniciava-se a aplicação da tarefa, mesmo que a criança não conseguisse acertá-lo.
A seguir, aplicava-se a Tarefa de Decisão Morfo-semântica (Besse et al., comunicação pessoal, setembro de 2005), dando-se a seguinte explicação à criança:

em português há palavras que são da mesma família, como, por exemplo, 'descobrir' e 'cobrir', ou seja, 'descobrir' vem de 'cobrir'. Acrescenta-se uma pequena coisa no início para fazer uma outra palavra. Outro exemplo é o caso de 'desfazer' e 'fazer', onde acrescenta o 'des' no início de 'fazer'. Porém, há palavras que também se iniciam por 'des', mas não vem de outra palavra.

Depois dessas considerações, voltava-se a pedir para a criança "então qual a palavrinha que é feita da mesma maneira que 'descobrir'? É 'deslizar' ou é 'desfazer'?”. Se a criança respondesse corretamente, iniciava-se a tarefa; do contrário, oferecia-se a forma correta explicando a razão. Depois do exemplo iniciava-se a aplicação da tarefa mesmo que a criança não conseguisse acertá-lo.

Ainda na mesma sessão era aplicada a Tarefa de Associação Morfo-Semântica (Nagy et al., 2006) fornecendo-se a seguinte explicação: "a palavra 'bola' e a palavra 'bolinha` são da mesma família. Já a palavra ‘bolo`e 'bolinha` não". Depois, um exemplo era feito junto com a criança: “a palavra bola é da mesma família que boleiro?". Respondendo de maneira esperada, começava-se a atividade e caso a resposta estivesse incorreta, dizia-se a palavra correta e apresentava-se novamente a explicação do exemplo. Também neste caso, depois do exemplo, iniciava-se a testagem, mesmo que a criança não obtivesse nenhum acerto.

Por último, aplicava-se a Tarefa de Analogia Gramatical (adaptada de Nunes et al., 1997) com a instrução de que muitas palavras poderiam ser relacionadas. A aplicadora apresentava um par de palavras relacionadas e pedia à criança que depois de ouvir uma palavra que ela criasse uma outra palavra relacionada como no exemplo. A tarefa era iniciada sempre pelo exemplo: "pedra-pedreiro; leite?" e assim, sucessivamente, eram pronunciadas as demais palavras-alvo.

$\mathrm{Na}$ segunda sessão foram aplicados os dois textos de Cloze, sendo pedido à criança que respondesse um de cada vez. Os textos foram sempre apresentados na mesma ordem. Solicitava-se que lessem a história até o fim e depois voltassem ao início e preenchessem os espaços com as palavras que julgassem dar mais sentido ao texto. No mesmo dia os dois sub-testes do WISC III (Vocabulário e Dígitos) foram aplicados segundo o procedimento padrão de aplicação. Na terceira e última sessão foram aplicados os dois sub-testes do Teste de Desempenho Escolar também seguindo o procedimento de aplicação do manual.

\section{Resultados}

Este estudo se propôs a investigar a relação entre a consciência morfológica e a compreensão de texto medida pelo Cloze. Para tanto, os resultados foram analisados em duas partes: na primeira parte exploramos a relação entre as tarefas de consciência morfológica e os escores no Cloze. $\mathrm{Na}$ segunda parte exploramos a especificidade desta rela- 
Mota, M. M. P. E., Lisboa, R., Dias, J., Gontijo, R., Paiva, N., Mansur-Lisboa, S., Silva, D. A. \& Santos, A. A. A. (2009). Relação entre Consciência Morfológica e Leitura Contextual Medida pelo Teste de Cloze.

ção, sendo que os resultados obtidos no WISC I foram utilizados como forma de controle da influência do desenvolvimento cognitivo na aquisição da leitura e escrita.

\section{Correlações entre o Cloze e as Medidas de Consciência Morfológica}

Entre as tarefas de consciência morfológica, apenas as tarefas de analogia gramatical e de associação morfosemântica de Nagy et al. (2006) atenderam aos critérios necessários para análises estatísticas paramétricas. Assim, efetuaram-se provas de correlação de Pearson entre essas tarefas, as tarefas do Cloze e essas medidas. Correlacionou-se também os escores do Cloze como vocabulário e tarefa de memória auditiva (sub-set do WISC). A Tabela 1. Mostra o resultado dessas correlações. Podemos ver pela tabela que os dois testes do Cloze correlacionaram-se de forma positiva e significativa com a tarefa de analogia $(r=0,47, p<0,01$ para o Cloze 1 e $r=0,52, p<0,01$ para o Cloze 2). Na tarefa de associação morfo-semântica os coeficientes foram significativos e positivos para o Cloze 2 $(r=0,25, p>0,01$ para o Cloze 1 e $r=0,58, p<0,01$ para o Cloze 2). O resultado da tarefa de dígitos também se correlacionou de forma significativa e positiva com os escores do Cloze e de consciência morfológica $(r=0,47, p<$ 0,01 para analogia; $r=0,32, p<0,01$ para associação morfosemântica; $r=0,36, p>0,01$ para o Cloze 1 e $r=0,52, p<$ 0,01 para o Cloze 2). Não houve correlações significativas entre os resultados do Cloze e o da medida de vocabulário das crianças.

A memória auditiva é uma medida de processamento fonológico, que se correlacionou tanto com o escore do Cloze como com o das medidas de consciência morfológica. É possível que a consciência morfológica seja produto de uma habilidade metalingüística mais geral resultante do processamento fonológico. Portanto esses resultados requerem que verifiquemos a especificidade da relação entre consciência morfológica e a leitura contextual, controlando a consciência fonológica.

Tabela 1

Correlações de Pearson entre as Tarefas de Consciência Morfológica e o Cloze (*p<0,05 e **p<0,01)

\begin{tabular}{lcccc}
\hline & Associação Morfo-Semântica & Analogia & Dígito & Vocabulário \\
\hline Cloze 1 & 0,25 & 0,47 & 0,36 & 0,14 \\
& $p=0,11$ & $p=0,002 * *$ & $p=0,02 *$ & $p=0,36$ \\
Cloze 2 & 0,36 & 0,52 & 0,54 & 0,2 \\
& $p=0,02 *$ & $p=0,001 * *$ & $p=0,001 * *$ & $p=0,15$ \\
\hline
\end{tabular}

\section{Correlações Parciais}

Os resultados das correlações de Pearson indicam que quanto maior a pontuação das crianças nas tarefas de consciência morfológica melhor era o desempenho delas na leitura contextual, medida pelo Cloze. No entanto, como já discutido na introdução desse trabalho precisamos saber se a consciência morfológica contribui de forma independente para a leitura contextual. As medidas de consciência fonológica não atenderam ao critério de normalidade, por isso utilizamos a medida de memória auditiva como controle para a capacidade de processamento fonológico. Outro problema é que é provável que o nível de escolaridade da criança (medido pela série), contribua para o desenvolvimento das habilidades metalingüísticas, mas como essa variável no nosso estudo é dicotômica não poderia entrar como medidas nas correlações. Por isso as correlações parciais foram realizadas para as duas séries de forma independente. A Tabela 2 mostra os resultados das correlações parciais.

Tabela 2

Correlações Parciais entre as Tarefas de Consciência Morfológica e os Escores no Cloze Controlando o Escore no Teste de Dígitos (*p<0,05 $\left.e^{* *} p<0,01\right)$

\begin{tabular}{lcccc}
\hline \multirow{2}{*}{ Testes de Cloze } & \multicolumn{2}{c}{ Primeira Série } & \multicolumn{2}{c}{ Segunda Série } \\
\cline { 2 - 5 } & Nagy & Analogia & Nagy & Analogia \\
\hline Cloze 1 & 0,34 & 0,08 & $-0,03$ & 0,49 \\
& $p=0,17$ & $p=0,72$ & $p=0,88$ & $p=0,02 *$ \\
Cloze 2 & 0,35 & 0,37 & 0,20 & 0,09 \\
& $p=0,14$ & $p=0,12$ & $p=0,37$ & $p=0,67$ \\
\hline
\end{tabular}

Podemos observar que para as crianças de primeira-série a relação entre as tarefas de consciência morfológica e o Cloze deixam de ser significativas quando se controla o processamento fonológico. No entanto, na segunda-série a tarefa de analogia continua a contribuir mesmo depois de se controlar o processamento morfológico $(r=0,49, p<0,01)$. 


\section{Discussão}

O presente estudo se propôs a investigar a relação entre os processamentos morfológico, fonológico e a leitura no contexto. Os resultados mostram que o processamento fonológico, medido pela tarefa de dígito, contribui para leitura contextual. Tunmer (1990) considera que um importante aspecto da compreensão de leitura é também a utilização de pistas grafo-fonêmicas associadas ao uso de informações contextuais.

Nossos resultados podem indicar que a hipótese de Tunmer (1990) é correta: algum tipo de processamento fonológico ocorre na leitura contextual, provavelmente quando a criança parcialmente decodifica as palavras. As correlações com a consciência morfológica parecem corroborar a idéia de que essa informação relativa à decodificação interage com informações sintático-semânticas oferecidas pelo conhecimento da morfologia da língua.

A relação entre o processamento da morfologia derivacional e a leitura contextual foi demonstrada através dos índices de correlação obtidos. As correlações positivas e significativas entre a medida de leitura contextual (Cloze) e as medidas de analogia gramatical e associação morfosemântica mostram que as crianças que tiveram maiores escores no Cloze foram aquelas com maiores escores nas tarefas de consciência morfológica. Estes resultados sugerem que além do processamento fonológico, o processamento morfológico contribui para leitura contextual. Embora correlações não estabeleçam relações de causa e efeito estes resultados indicam que essa questão deve ser investigada em estudos que possam estabelecer se há uma relação causal entre essas variáveis.

Os resultados aqui obtidos mostram também que a relação entre o processamento morfológico e a leitura contextual é específica. Mesmo controlando a variável 'dígitos' os escores da tarefa de analogia gramatical continuam se correlacionando de forma positiva e significativa com a tarefa do Cloze 1. No entanto, este resultado só ocorreu para as crianças de segunda-série, o que leva a cogitar se o Cloze é uma medida apropriada para crianças de $1^{\mathrm{a}}$ série, não só por ter o seu léxico reduzido, mas principalmente pela precariedade de sua habilidade de escrita que pode ter sido responsável pelas pontuações mais baixas. Vale lembrar que o estudo original de evidências de validade e precisão dos testes aqui utilizados não incluía amostras de primeira série, embora outros o tenham feito (Carvalho, 2006; Cunha, 2006).

Porém, Rego (1995) num estudo realizado com crianças brasileiras ainda mais jovens que a desse estudo encontrou uma relação entre a consciência sintática e a leitura contextual, mas não com a consciência fonológica. A autora concluiu que a utilização de pistas grafo-fonêmicas não ocorria na leitura no contexto no português.

A medida de consciência fonológica utilizada pela autora diferiu da nossa, visto ter sido uma medida de aliteração. Nossa medida envolveu, além do processamento fonológico, o processamento da memória de trabalho. Mais estudos são necessários para estabelecer qual é a relação entre essas diferentes variáveis e a leitura contextual.
Uma hipótese possível pode ser formulada se analisarmos os trabalhos de Nunes et al. (1997) que propuseram um modelo de desenvolvimento da relação entre a consciência morfológica e a escrita de palavras flexionadas. Os autores consideram que no começo da aquisição da escrita, a criança precisa consolidar o conhecimento do princípio alfabético. Somente após esse conhecimento estar consolidado é que a criança começa a levar em conta os aspectos morfológicos da língua na escrita. Em acréscimo, observam que a consciência morfológica começa a ter um peso maior no conhecimento da escrita a partir da terceira ou quarta-série.

\section{Considerações Finais}

Os resultados aqui apresentados parecem sugerir um modelo para a relação entre o processamento morfológico e a leitura contextual. Na primeira série, as crianças podem ainda estar com sua atenção focada na consolidação do princípio alfabético. Por isso as medidas de consciência morfológica podem não ter contribuído de forma significativa e independente para a leitura contextual. A partir da segunda série as crianças, já com o princípio alfabético consolidado, podem começar a utilizar outras informações lingüísticas para compreender a complexidade do sistema ortográfico no português. Esse modelo proposto deve ser testado através de estudos longitudinais que utilizem análise de caminho (path analysis).

Uma última questão de cunho metodológico diz respeito à maneira em que o Cloze foi aplicado e corrigido. Para evitar a subjetividade na avaliação das respostas foi utilizada a correção literal na correção do Cloze. Dessa forma, sinônimos, palavras escritas de forma errada ou sem acento foram consideradas como erradas. Embora isso não invalide o Cloze como uma medida de leitura contextual, faz com ele seja também uma medida de escrita. Estudos futuros podem separar essa variável, pedindo para as crianças lerem o texto e completarem as palavras de forma oral.

\section{Referências}

Bowey, J. (2005). Grammatical sensitivity: Its origins and potential contribution to early reading skill. Journal of Experimental Child Psychology, 90, 318-343.

Bradley, L., \& Bryant, P. (1983). Categorizing sounds and learning to read: A causal connection. Nature, 301, 419-421.

Bradley, L., \& Bryant, P. (1985). Children's reading problem. Oxford, UK: Basil Blackwells.

Capovilla, A., \& Capovilla, F. (2000). Efeitos do treino de consciência fonológica em crianças com baixo nível sócio-econômico. Psicologia: Reflexão e Crítica, 13(1), 7-24.

Cardoso-Martins, C. (1995). Consciência fonológica e alfabetização. Petrópolis, RJ: Vozes.

Cardoso-Martins, C. (1997). A sensibilidade e rima e ao fonema e a aquisição da leitura em crianças normais e indivíduos com a síndrome de Down: Um estudo correlacional. Tese de Doutorado não-publicada, Universidade Federal de Minas Gerais, Belo Horizonte, MG. 
Mota, M. M. P. E., Lisboa, R., Dias, J., Gontijo, R., Paiva, N., Mansur-Lisboa, S., Silva, D. A. \& Santos, A. A. A. (2009). Relação entre Consciência Morfológica e Leitura Contextual Medida pelo Teste de Cloze.

Carlisle, J. (1988). Knowledge of derivational morphology and spelling ability in fourth, six, and eight graders. Applied Psycholinguistics, 9, 247-266.

Carlisle, J. (1995). Morphological awareness and early reading achievement. In L. Feldman (Ed.), Morphological aspects of language processing (pp. 189-211). Hillsdale, NJ: Lawrence Erlbaum.

Carlisle, J. (1996). An exploratory study of morphological errors in children's written stories. Reading and Writing: An Interdisciplinary Journal, 8, 61-72.

Carlisle, J. (2000). Awareness of the structure and meaning of morphologically complex words: Impact on reading. Reading and Writing: An Interdisciplinary Journal, 12, 169-190.

Carlisle, J., \& Fleming, J. (2003). Lexical processing of morphologically complex words in the elementary years. Scientific Studies of Reading, 7(3), 239-253.

Carvalho, L. (2006). Evidência de validade do Bender (B-SPG). Tese de doutorado não-publicada, Universidade São Francisco, Itatiba, SP.

Chomsky, N., \& Halle, M. (1968). The sound patterns of English. New York: Harper \& Row.

Colé, P., Marec-Breton, N., Royer, C., \& Gombert, J. E. (2003). Morphologie des mots et apprentissage de la lecture. Reeducation Orthophonic, 213, 57-60.

Correa, J. (2005). Avaliação da consciência morfossintática na criança. Psicologia: Reflexão e Crítica, 18(1), 91-97.

Cunha, N. B. (2006). Instrumentos para avaliação da leitura e escrita: Estudos de validade. Tese de doutorado não-publicada, Universidade São Francisco, Itatiba, SP.

Cunningham, A. E. (1990). Implicit versus explicit instruction in phonemic awareness. Journal of Experimental Child Psychology, 50, 426-444.

Deacon, S., \& Kirby, J. (2004). Morphological awareness: Just "more phonological"? The roles of morphological and phonological awareness in reading development. Applied Psycholinguistics, 25, 223-238.

Gombert, J. E. (1992). Metalinguistic development. Hertfordshire, UK: Harverster Wheatsheaf.

Goswami, U., \& Bryant P. (1990). Phonological skills and learning to read. London: Lawrence Erlbaun.

Guimarães, S. (2003). Dificuldades no desenvolvimento da lectoescrita: O papel das habilidades metalinguísticas. Psicologia: Teoria e Pesquisa, 19(1), 33-45.

Lehtonen, A., \& Bryant, P. (2005). Active players or just passive bystanders? The role of morphemes in spelling development in a transparent orthography. Applied Psycholinguistics, 26(2), 137-155

Maki, R. H., Schields, M., Wheeler, A. E., \& Zacchini, T. L. (2005). Individual differences in absolute and relative metacomprehension accuracy. Journal of Educational Psychology, 97(4), 723-731.

Maluf, M. R., \& Barrera, S. D. (1997). Consciência fonológica e linguagem escrita em pré-escolares. Psicologia: Reflexão e Crítica, 12(1), 125-145.

Mann, V. (2000). Introduction to special issue on morphology and the acquisition of alphabetic writing systems. Reading and Writing: An Interdisciplinary Journal, 12, 143-147.

Marec-Breton, N., \& Gombert, J. (2004). A dimensão morfológica nos principais modelos de aprendizagem da leitura. In M. R. Maluf (Ed.), Psicologia educacional: Questões contemporâneas (pp. 105-122). São Paulo, SP: Casa do Psicólogo.

Nagy, W., Berninger, V., \& Abbot, R. (2006). Contributions of morphology beyond phonology to literacy outcome of upper elementary and middle-school students. Journal of Educational Psychology, 98(1), 134-147.
Nicholson, T. (1993). The case against context. In G. Thompson, W. Tunmer, \& T. Nicholson (Eds.), Reading acquisition processes (pp. 91-103). Clevedon, UK: Multilingual Matters.

Nunes, T., Bindman, M., \& Bryant, P. (1997). Morphological strategies: Developmental stages and processes. Developmental Psychology, 33(4), 637-649.

Pinheiro, A. M. V. (1996). Contagem de freqüência de ocorrência de palavras expostas a crianças na faixa pré-escolar e séries iniciais do $1^{o}$ grau [Computer software]. São Paulo, SP: Associação Brasileira de Dislexia.

Plaza, M., \& Cohen, H. (2003). The interaction between phonological processing, syntactic awareness, and naming speed in the reading and spelling performance of first-grade children. Brain and Cognition, 53, 257-292.

Plaza, M., \& Cohen, H. (2004). Predictive influence of phonological processing, morphological/syntactic skill, and naming speed on spelling performance. Brain and Cognition, 55, 368-373.

Queiroga, B., Lins, M., \& Pereira, M. (2006). Conhecimento morfossintático e ortografia em crianças do ensino fundamental. Psicologia: Teoria e Pesquisa, 22(1), 95-99.

Rego, L. (1995). Diferenças individuais na aprendizagem inicial da leitura: Papel desempenhado por fatores metalingüísticos. Psicologia: Teoria e Pesquisa, 11(1), 51-60.

Rego, L., \& Bryant, P. (1993). The connections between phonological, syntactic and semantic skills and children's reading and spelling. European Journal of Psychology, 3, 235-246.

Santos, A. A. A. (1996). A influência da consciência fonológica na aquisição da leitura e da escrita. In F. F. Sisto, G. C. Oliveira, L. D. T. Fini, M. T. C. C. Souza, \& R. P. Brenelli (Eds.), Atuação psicopedagógica e aprendizagem escolar (pp. 213247). Petrópolis, RJ: Vozes.

Santos, A. A. A. (2004). O Cloze como técnica de diagnóstico e remediação da compreensão em leitura. Interação em Psicologia, 8(2), 217-226.

Santos, A. A. A. (2005). O Teste de Cloze como instrumento de diagnóstico e de desenvolvimento da compreensão em leitura (Tech. Rep.). Itatiba, SP: Universidade São Francisco.

Santos, A. A. A., Primi, R., Taxa, F., \& Vendramini, C. M. M. (2002). O teste de Cloze na avaliação da compreensão em leitura. Psicologia: Reflexão e Crítica, 15(3), 549-560.

Stanovich, K. E. (1980). Toward an interactive-compensatory model of individual differences in the development of reading fluency. Reading Research Quarterly, 16, 32-71.

Stein, L. M. (1994). TDE - Teste de desempenho escolar: Manual para aplicação e interpretação. São Paulo, SP: Casa do Psicólogo.

Sterling, C. (1992). Introduction to the psychology of spelling. In C. Sterling \& C. Robson (Eds.), Psychology, spelling \& education (pp. 1-15). Adelaide, Austrália: Multilingual Matters.

Tunmer, W. (1990). The role of language prediction skills in beginning reading. New Zealand Journal of Educational Studies, 25(2), 95-112.

Wechsler, D. (1991). WISC-III: Escala de inteligência Weschsler para crianças. São Paulo, SP: Casa do Psicólogo.
Recebido: $30 / 03 / 2008$ $1^{a}$ revisão: $04 / 06 / 2008$ $2^{a}$ revisão: $15 / 09 / 2008$ Aceite final: 10/10/2008 